\title{
Safe Controlled Storage of SVBR-100 Spent Nuclear Fuel in the Extended-Range Future
}

\author{
Georgy Toshinsky ${ }^{1,2 *}$, Sergey Grigoriev², Alexander Dedul², Oleg Komlev², Ivan Tormyshev
}

${ }^{1}$ JSC “SSC RF-IPPE”, Obninsk, Russia

${ }^{2}$ JSC “AKME-Engineering”, Moscow, Russia

Email: *toshinsky@ippe.ru

How to cite this paper: Toshinsky, G., Grigoriev, S., Dedul, A., Komlev, O. and Tormyshev, I. (2019) Safe Controlled Storage of SVBR-100 Spent Nuclear Fuel in the Extended-Range Future. World Journal of Nuclear Science and Technology, 9, 127-139. https://doi.org/10.4236/wjnst.2019.93009

Received: October 17, 2018

Accepted: July 2, 2019

Published: July 5, 2019

Copyright $\odot 2019$ by author(s) and Scientific Research Publishing Inc. This work is licensed under the Creative Commons Attribution International License (CC BY 4.0).

http://creativecommons.org/licenses/by/4.0/

\begin{abstract}
Experience of operating reactor facilities (RF) with lead-bismuth coolant (LBC) has revealed that it is possible to perform safe refueling in short terms if the whole core is replaced and a kit of the special refueling equipment is used. However, comparing with RFs of nuclear submarines (NS), in which at the moment of performance of refueling the residual heat release is small, at RF SVBR-100 in a month after the reactor has been shut down, at the moment of performance of refueling the residual heat release is about $500 \mathrm{~kW}$. Therefore, it is required to place the spent removable unit (SRU) with spent fuel subassemblies (SFSA) into the temporal storage tank (TST) filled with liquid LBC, in which the conditions for coolant natural circulation (NC) and heat removal via the tank vessel to the water cooling system are provided. After the residual heat release has been lowered to the level allowing transportation of the TST with SRU in the transporting-package container (TPC), it is proposed to consider a variant of TPCs transportation to the special site. On that site after the SRU has been reloaded into the long storage tank (LST) filled with quickly solidifying liquid lead, the TPCs can be stored during the necessary period. Thus, the controlled storage of LSTs is realized during several decades untill the time when SNF reprocessing and NFC closing are becoming economically expedient. On that storage, the four safety barriers are formed on the way of the release of radioactive products into the environment, namely: fuel matrix, fuel element cladding, solid lead and steel casing of the LST.
\end{abstract}

\section{Keywords}

Spent Nuclear Fuel, Controlled Storage, Lead-Bismuth Coolant, Safety Barriers, Radioactive Waste 


\section{Introduction}

The design of reactor SVBR-100 allows its operation in such a way that without changes in design that reactor can operate using different types of fuel both in an open nuclear fuel cycle (NFC) with postponed reprocessing of spent nuclear fuel (SNF) and in the closed NFC [1]. The option for the fuel and NFC type is determined by economical expedience and technological mastering of the fuel and fuel cycle.

It can be expected that at the nearest first stage of implementation of fast reactors (FR) in the nuclear power (NP) in conditions of low costs of natural uranium and services on its enrichment, the operation of reactor SVBR-100 with use of oxide uranium fuel in an open NFC with postponed reprocessing of SNF will be more economically expedient than that in the closed NFC despite the fact of significantly higher (approximately by a factor of $2-2.5$ as compared with that of VVER-1000 reactors) specific (per $1 \mathrm{kWh}$ ) consumption of natural uranium. As an example, it was demonstrated by the results of conceptual project of the modular NPP with reactors SVBR-75/100 cooled by heavy liquid-metal coolant (HLMC) lead-bismuth alloy (2002) [2]. Use of that fuel enriched in less than $20 \%$ with postponed reprocessing of SNF is also the most expedient for the reasons of nonproliferation that is important when those reactors are exported to developing countries.

Of course, when the costs of natural uranium and the cost of SNF storage increase much while the SNF reprocessing and its cost are decreasing, the changeover to the closed NFC will become economically expedient. At that point, reactors SVBR-100 will operate in a mode of fuel self-providing with a breeding ratio (BR) slightly exceeding one. Launching of FRs using uranium fuel with further changeover to the closed NFC (as it is shown in [3]) is more economically expedient than launching of FRs using mixed uranium-plutonium fuel with the use of plutonium extracted upon reprocessing of thermal reactors (TR) SNF.

At that point, there is no necessity to construct the expensive factories on reprocessing of TR SNF and manufacturing of uranium-plutonium fuel prior to launching of FRs ${ }^{1}$.

However, operation of FRs with postponed reprocessing of SNF will require to find the solution to the issue of safe controlled and economic storage of the SNF with retention of the opportunity to use it upon NFC closing.

\section{SNF Management Problems}

Up to nowadays, the problem of NPP SNF management has not been solved in full in any country. That is a challenge to the current NP and is a cause of concern for a certain part of the population and national governments because of high long-lived radioactivity accumulated in the SNF. That fact and some other reasons, namely: safety, economics, nonproliferation, are hampering NP devel${ }^{1}$ In Japan the cost of Rokkasho Reprocessing Plant (RRP) with an annual capacity to reprocess 800 tonnes of SNF is $\$ 25$ billion. This is equivalent to the capacity to reprocess spent nuclear fuel from 40 PWR type reactors, the capacity of each reactor is about $1 \mathrm{GWe}$. 
opment. To hasten the process of finding the solution to that postponed problem, the following ethical principle has been put forward: "Radioactive waste shall be managed in such a way that will not impose undue burdens on future generations" [4].

Though the principal scientific ways for finding the solution to that problem are clear in general terms, the practical realization of the highlighted problem is requiring performance of the corresponding $\mathrm{R} \& \mathrm{D}$, demonstration of the entire cycle of SNF management and harmonization of national strategy and policy in the area of nuclear fuel cycle in the world.

That is conditioned by the fact that now the nuclear community does not possess the necessary knowledge, experience and opportunities for finding the safe and economically efficient solution to that complex problem. In the process of development of SNF management methods, it should be accounted that at the existing technologies of SNF reprocessing, two first defense barriers are damaged, namely: fuel matrix and fuel element cladding. And the fuel, in which the huge amount of radioactivity has been accumulated, is converted from a solid state into liquid one (or gas phase required for gas-fluoride technology) when radioactivity release into the environment is much possible.

When the most developed water-chemical reprocessing of SNF is used, arising of the accidents caused by the emergence of over-critical configuration or concentration of fissile nuclei cannot be excluded as water is the best moderator of neutrons. The Tokaimura Criticality Event occurred on September 30, 1999 in Japan was among those accidents. In 1957 at "Mayak" (a plutonium production site for nuclear weapons and nuclear fuel reprocessing plant, Chelyabinsk Region, Russia) the catastrophic exhaust of radioactivity occurred in the repository for liquid radioactive wastes received from reprocessing of SNF of weapon uranium-graphite reactors. Moreover, in the process of SNF reprocessing, it is more difficult to perform the account and control of nuclear fissile materials (NFM) that is heightening the risk of their unauthorized proliferation.

At present, there are three approaches used to find the solution to SNF management.

\subsection{The SNF Is the NP Radioactive Waste}

The SNF is considered as the NP radioactive waste that must be finally buried in deep geological formations, where SNF radioactive substances can be securely isolated for hundreds of thousands of years.

However, in that case, the following conflict appears, namely: a desire to bury the SNF as deep as possible for its maximal safe isolation from the biosphere and opportunity to remove the residual heat. Heat removal via thick rock layers by thermal conductivity will take a very long time before the residual heat is reduced to the permitted level eliminating the necessity for temperature monitoring and organized heat removal. Otherwise, it will be necessary to provide heat removal into the atmosphere by organizing a multiple branch system of 
air-supply and exhaust ducts. For a long time, it will be necessary to provide temperature monitoring of storage packages and air flow rate in the air ducts, via which the radionuclides can be released in the biosphere in an event of degradation of protection barriers. It will be also required to organize reliable accounting, control and physical protection of SNF packages with NFMs.

During the last 30 - 40 years that approach has been taken up in the USA. The Yucca Mountain Nuclear Waste Repository was built on the site located in the mountains in the State of Nevada. That geological storage facility was provided for final burial of packages with spent fuel subassemblies (SFSA) after they had been cooled for many years in the plant spent nuclear fuel storages (SNFS) purposed to reduce radioactivity and corresponding heat release. The SFSAs should be located in special cans equipped by multi-barrier shielding.

The cost of that repository equipped with ventilation channels, and which required 40 miles of tunnels to store 70,000 metric tons of SNF was estimated as $\$ 13.5$ billion [5]. So, a special fund was established to build the Yucca Mountain project [6]. All nuclear power plants had to pay a tax of 0.1 cent on each kilowatt-hour of produced electricity. By estimations, the cost for 100 years of operation will reach $\$ 90$ billion. The repository square is $2 \times 2 \mathrm{~km}^{2}$.

Currently, it is considered that the highlighted approach does not comply with requirements of large-scale NP development and implementation of the Yucca Mountain repository is held up.

The main reasons for that are presumed to be as follows:

First, as a matter of fact, the NP radioactive waste (RAW) are fission products, which mass content in the SNF is as follows: about $5 \%$ for thermal reactors (TR), about $10 \%$ for fast reactors (FR). Others are as follows: uranium-238 (about $90 \%$ ), which is a nuclear raw material for producing of plutonium-239 for the future NP based on FRs operating in the closed NFC and eliminating the problem of NP fuel providing for centuries (within the reasonable scales); built up plutonium-239 along with its higher isotopes, and unburned out uranium-235 that is a nuclear fuel, which will be used upon NFC closing; small amount of transuranium elements (so-called minor actinides: isotopes of neptunium, americium, curium), which are generated while capturing of neutrons without fission by uranium-235 and plutonium-239 and their daughter nuclei.

Thus, general application of that approach can doom the NP to use as fuel only the rare isotope of uranium-235 (that is about $0.7 \%$ in natural uranium), which economically available resources can be expired in the nearest $50-100$ years upon the high paces of development of the NP based on existing TRs operating in the open NFC. NFC closing for TRs, in which due to degradation of nuclear properties of plutonium a single recycle of plutonium is possible, is reducing the specific consumption of natural uranium by a little without finding the solution to the other problems of SNF management. Such fuel cycle is realized, e.g. in France. However, at this point, the cost of mixed oxide uranium-plutonium fuel (MOX fuel) is by a factor of 4.5 times higher than the cost 
of uranium fuel [7]. Thus, the cost of produced electricity is heightened approximately by $20 \%$ [7].

In the USA one of major reasons for final burial of the SNF was fear of unauthorized proliferation of plutonium in an event of its releasing from SNF in the process of reprocessing in the closed NFC.

Second, though the content of minor actinides (MA) in the SNF is low, it is MA but not fission products, which are determining the long-lived radioactivity of SNF, as their half-life is hundreds of thousands of years (against dozens of years for the most of fission products). For such long storage period, the geologists cannot assure the absence of tectonic shifts in the earth's crust, which can cause destruction of protection barriers in the SNF packages and release of radioactive products into the ecosystem.

\subsection{Controlled Storage of SNF}

At present, long (dozens of years) controlled storage of SNF in plants or central SNFSs is realized almost in all countries.

Currently that method of SNF management is the cheapest and meets the requirements of plutonium nonproliferation because in the SNFS the last is under protection of strong gamma-irradiation of fission products that facilitates account and control of the NFMs and leaves open the possibility to use SNF in the closed NFC when the conditions in economics become ready for that.

Along with that, the following limitations are peculiar to the existing technologies:

- Long storage of SNF in the cooling water pools are resulting in the development of corrosion processes in fuel elements claddings and opportunity of radioactive contamination of water.

- The necessity for uninterruptible electricity supply for the purpose to provide operation of cooling systems. In compliance with that requirement is resulting in water boil-off, heating of fuel, steam-zirconium reaction with generation of hydrogen in large amounts, explosions and radioactivity exhausts (Fukushima 1). For that reason, for a long time, there is in practice the process of changeover to "dry" cask storage with cooling realized by air natural circulation after the SNF has been cooled in the water pool for three years or more for the purpose to reduce the residual heat. Such newly built central "dry" cask storage repository is implemented on the site of Mining and Chemical Combine (Zheleznogorsk, Krasnoyarsk Krai, Russia).

- The cost of SNF storage is increasing while the number of NPPs and their operation time are growing much. Though the "dry" SNFSs with air natural cooling does not require large operating expenses, the capital costs needed for their construction are large due to the necessity to protect them against external impacts. These costs will be decreasing with increasing storage density measured in metric tons of heavy metal per one square meter of the repository.

Along with that when the issues of storage of power reactors SNF were 
considered at the IAEA Scientific Forum held within the frameworks of the 47th IAEA General Conference (Vienna, 2003), the certain countries expressed a desire to extend the SNF storage time up to 100 years and over. They explained that by the factor of delays in implementation of the programs on SNF burial in geological repositories. In addition, significant expanding of the time of SNF storage in "dry" repositories makes a possible saving of financial resources for the construction of geological repositories. Absence of social agreement on the issue concerning how to consider the spent fuel, namely: as a waste or fuel for the future NP, lack of political will in activities on options for the sites for geological repositories and their construction are also the motivation in the certain countries to extend the period of "dry" storage of the SNF.

\subsection{NFC Closing}

Organizing of the closed NFC with the implementation of FRs and large-scale reprocessing of TR and FR SNF in a unified NFC. Thus, the fission products are separated for their further immobilization and final isolation (really, radioactive wastes). The remaining uranium and built plutonium are used for manufacturing of fresh fuel. At the same time, the task of noticeable reduction of amounts of stored SNF and unloading of repositories is solved.

To solve the problem of MA incineration, the different methods of nuclear transmutation of MA in fast critical or subcritical (accelerator driven) reactors are studied. In those reactors, the long-lived MA are fissioned by fast neutrons and transmuted into relatively short-lived fission products. After required cooling in the controlled repository those fission products can be vitrified similar to fission products of uranium and plutonium and then safely buried in geological repositories.

Realization of the highlighted approach needs implementation of the high number of FRs in the NP structure, which allow increasing approximately by a factor of hundred the efficiency of use of energy potential of natural uranium as compared with that of TRs. In many countries the FRs have been highly developed since the second half of the last century due to the existence of two challenges, namely: 1) predictable high paces of NP development, 2) insufficiency in explored economically available resources of natural uranium.

Sodium cooled fast reactors with a breeding ratio exceeding one $(\mathrm{BR}>1)$ could provide short plutonium doubling time and upon operating in the closed NFC made possible elimination of limitations on the paces of implementation of new nuclear power plants (NPPs)due to insufficiency in economically available resources of natural uranium. However, they were more expensive as compared with TRs operating in the open NFC, and were not economically demanded in conditions of low costs of natural uranium and services on its enrichment.

\section{Possible Duration of Temporal SNF Storage Prior to Reprocessing}

At present it is not easy to determine the time when reprocessing of the SNF 
with recycling of plutonium and MA, separation of fission products and their final isolation will become economically expedient. That time will depend on specific consumption of natural uranium by existing TRs and its contribution into a fuel component of the electricity cost, forecast for resources of natural uranium and their dependence on the cost of natural uranium, escalation of natural uranium costs (now they are not increasing), prospect for the paces of NP development in the current century, the cost of SNF storage and reprocessing, the cost of manufacturing of refabricated fuel, economic characteristics of fast reactors, the cost of final isolation of long-lived RAW.

For the purpose to make a preliminary decision for NFC variants for future large-scale NP, the comparative economic analysis of the open NFC with postponed SNF reprocessing and closed NFC for the USA conditions was performed in the Massachusetts Institute of Technology (MIT Reports) [7] and earlier [8]. In those Reports, it was revealed that up to the end of the current century the thermal reactors operating in the open NFC would not lose their competitiveness because of rising in the cost of natural uranium.

However, as the commercial FRs operating in the closed NFC have not been implemented yet, there are many uncertainties in estimations of their economic characteristics. That point is concerning both economic characteristics of FRs and economic parameters of the closed NFC. All highlighted points will effect on forecasting determination of the time for economically expedient NFC closing. The same can be said about the assessment of economically available resources of natural uranium and paces of NP development.

According to the common geological regularity, on average the mineral resources are growing in proportion to the squared cost that the consumer is ready to pay. Of course, that refers to uranium as well. For instance, according to the data presented by UICA (Uranium Information Centre Australia) [9], doubling of the cost of uranium $(\$ 30 / \mathrm{kg}$ ) that existed in 2000 could presumably result in 10 times more growth of natural uranium resources, which cost is $\$ 80 / \mathrm{kg}$ or less, i.e. the resources of natural uranium will increase from 3 to 30 million metric tons.

Along with that, even considerable increase in the cost of uranium extracted from depleted deposits can only slightly raise the cost of electricity due to the fact that the cost contribution of natural uranium into the cost of produced electric power is low. For example, according to the data given in [8], in case the cost of uranium is increased by a factor of twice, i.e. from 30 to $\$ 60 / \mathrm{kg}$, the electricity cost of the existing NPPs is growing by $0.11^{\circ}$ cent per kilowatt hour or by $2.2 \%$.

When uranium is extracted together with other minerals, the uranium resources are growing appreciably along with depletion of uranium content in the extracted ore. The example is phosphate deposits where uranium content is low, namely from 10 to $300 \mathrm{ppm}$. However, it is forecasted in [10] that in the uranium-ore deposits the mentioned content of uranium is contained in approximately 22 million metric tons of uranium. 
According to the data presented in [7], electricity produced by light water reactors (LWR) will be competitive until the uranium cost reaches the values in the range of $\$ 300$ - $\$ 400 / \mathrm{kg}$. The highlighted cost range is covering the range of predicted costs of uranium extracted from sea water. However, even provided that forecast is true, it is difficult to agree that the SNF is a radioactive waste that must be buried once and for all.

Among the world countries, which possess the uranium resources, Russia, where the uranium cost is less than $\$ 130 / \mathrm{kg}$ thus providing competitiveness of the NP based on TRs, is on the fourth place, right after Australia, Kazakhstan and Canada [10]. These resources (both determined and forecasted ones) are as much as 1.3 million metric tons. However, because of the low market costs of natural uranium, at present the certain deposits are unprofitable. Today the repeated use of waste uranium that has been piled in great amounts at the uranium enrichment plants is more profitable. The additional resource is the use of regenerated uranium obtained on the extraction of weapon plutonium at the Mayak plant for its after-enrichment to the content of ${ }^{235} \mathrm{U}$ in natural uranium with the application of the most effective gas-centrifugal technology for separation of isotopes.

On the assumption that till the end of the century the average value of overall installed power capacities of NPPs with VVER in Russia is about $70 \mathrm{GW}$ (it corresponds to the average pace of annual implementing in operation of $1.5 \mathrm{GW}$ or more with account of decommissioning of power-units) and $115 \mathrm{GW}$ is a value of overall installed power capacities of NPPs in 2100, it will be required about 1.2 million metric tons of natural uranium upon reactors operation in the open NFC with postponed reprocessing of SNF.

Bearing in mind it is unlikely that by the end of the century the total power capacities of SVBR-100 reactors will exceed $10 \mathrm{GW}$ while their serial implementation is beginning from 2030, their operation in the open NFC with postponed reprocessing, provided it is profitable, will require 280 thousands of tons of natural uranium.

With due account of the highlighted above, it can be expected that prior to the SNF has been involved in the closed NFC, duration of the period of storage of SVBR-100 SNF can take dozens of years. For that reason, the development of the concept of sufficiently long controlled storage of SNF from SVBR-100 reactors is expedient.

\section{The Concept of Safe Controlled Storage of SNF from SVBR-100 Reactors}

For the design of experimental-industrial power unit (EIPU) with reactor facility (RF) SVBR-100 the variant of cassette-by-cassette extraction of the SFSA with their further placing in capsules filled with lead was adopted. Then those capsules had to be stored for a long time in the in-plant "honeycomb" type storage facility with natural air cooling that provided removal of residual heat from the 
SFSA. The storage duration can be hundred of years or more because on the way of radioactivity release into the environment there are four safety barriers, which are not subject to damaging factors during storage.

Along with that, the experience of operation of RF with lead-bismuth coolant (LBC) has revealed that it is possible to perform safe refueling in short terms provided the whole core is replaced with the use of the special refueling equipment set [11]. At that point, cooling and long storing of SNF extracted from the reactor were realized in long storage tanks (LST) filled with liquid LBC, which was solidifying after that. Removal of residual heat was performed via the LST casing by natural circulation (NC) of atmospheric air. By present, the obtained storage time without any signs of radioactivity release is about fifty years. Such technology simplifies the technological process of refueling, shortens its duration, and makes possible diminishing of dimensions of the main building and reducing of its cost.

However, in contrast to the nuclear submarines (NS) RFs, in which the residual heat was low when unloading was performed, for RF SVBR-100 in a month from the moment of reactor shutdown the residual heat upon unloading is about $500 \mathrm{~kW}$. For that reason, it is necessary to place the spent removable unit (SRU) with SFSA into the temporal storage tank (TST) filled with liquid LBC, in which there are conditions for NC of LBC and removal of heat via the tank casing to the water cooling system.

In a year of cooling the heat, decay is reduced to $170 \mathrm{~kW}$. That makes it possible to extract the TST together with SRU out of the shaft and install it in the in-plant transport-package container (ITPC), where further cooling of the SRU is realized till complete solidification of LBC in the TST. And that will take ten years. TST cooling in the ITPC is realized by natural circulation of atmospheric air. For the purpose to reduce the cost of LBC in the TST, the LBC can be manufactured from lead and bismuth of cheap technical grades instead of those of reactor fineness.

After the residual heat has been decreased to the level that makes possible transportation of the TST with SRU in the transport-package container (TPC) without taking the special measures on organizing of heat removal and meeting of the railway requirements and normative documentation requirements on transportation of packages with nuclear fissile materials, the following two variants of SNF management are possible:

1) To transport the TPCs to the Mayak plant, where unloading of SRUs from the TST is performed and then dismantled for further reprocessing of the SNF. The technology for performance of works on the unloading of the SRU and description of the equipment is presented in paper [11]. That variant of SNF reprocessing can be realized at the Mayak plant on the expiration of 10 years of SNF storage in the ITPCs on the NPP site provided SNF reprocessing has been organized by that time.

2) To transport the TPCs to the special site. At that site after the SRUs have 
been reloaded into the LSTs filled with quickly solidifying liquid lead (on ten years of cooling the residual heat is about $25 \mathrm{~kW}$ and can be easily removed by atmospheric air NC under the temperature of the LST wall being not more than $200^{\circ} \mathrm{C}$ ), the LST are stored during the required time. Thus, the controlled storage of LSTs is realized for several decades up to the time when SNF reprocessing and NFC closing are becoming economically expedient. Upon that storage, the four safety barriers are formed on the way of releasing of radioactive products into the environment, namely: fuel matrix, fuel element cladding, hard lead and steel casing of the LST. In addition to the reduction of the cost, replacement of LBC by lead is providing more reliable protection of SRUs against extremal external effects due to the higher temperature of lead solidifying $\left(327^{\circ} \mathrm{C}\right)$. The additional shielding is a reinforced concrete hood $(\mathrm{RCH})$, which walls are of a required thickness, that covers each LST. By performed assessments, the RCH thickness is within the range of $(50-100) \mathrm{cm}$.

It is expected that separation of functions of SRU transportation in the expensive TPCs, whose number is not large, and long storage of the LSTs protected against external effects by comparatively cheap $\mathrm{RCHs}$ can be more economically expedient than use of a large number of dual-purposed containers, the cost of each is about $\$ 2$ million [5].

That practice of temporal controlled storage of thermal reactors SNF in the reinforced concrete containers on the open site is realized in the USA [7] and in Germany where cast-iron dual-purposed containers are used for SNF storage and transportation [5]. "Dry" storage facility of SNF in the USA is shown in Figure 1. CASTOR V (Interim storage facility Surry) is shown in Figure 2. With reference to the data presented in [7], the cost of such storage heightens the cost of electricity only by $1 \%-2 \%$ upon the density of SNF storage being 0.5 tons of heavy metal per square meter.

Upon that density of storage on the site, which square is $200 \times 200 \mathrm{~m}^{2}$, for safe controlled storage it is possible to place 13,000 tons of the SNF from reactors SVBR-100 (about 1500 LSTs with spent removable units). That corresponds to

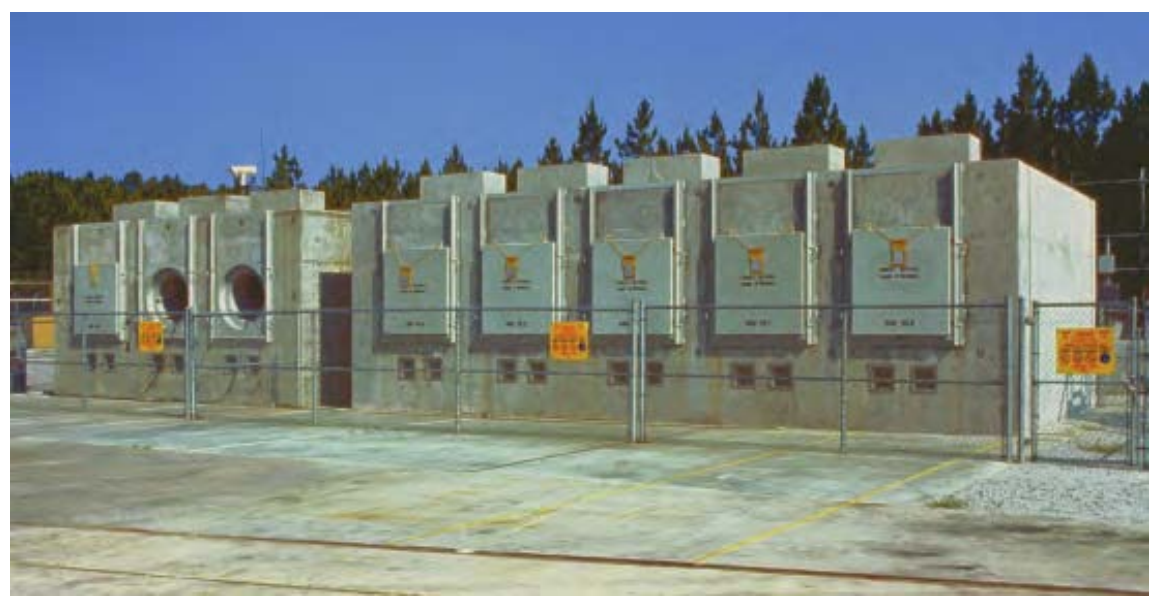

Figure 1. "Dry" storage facility of SNF in the USA. 


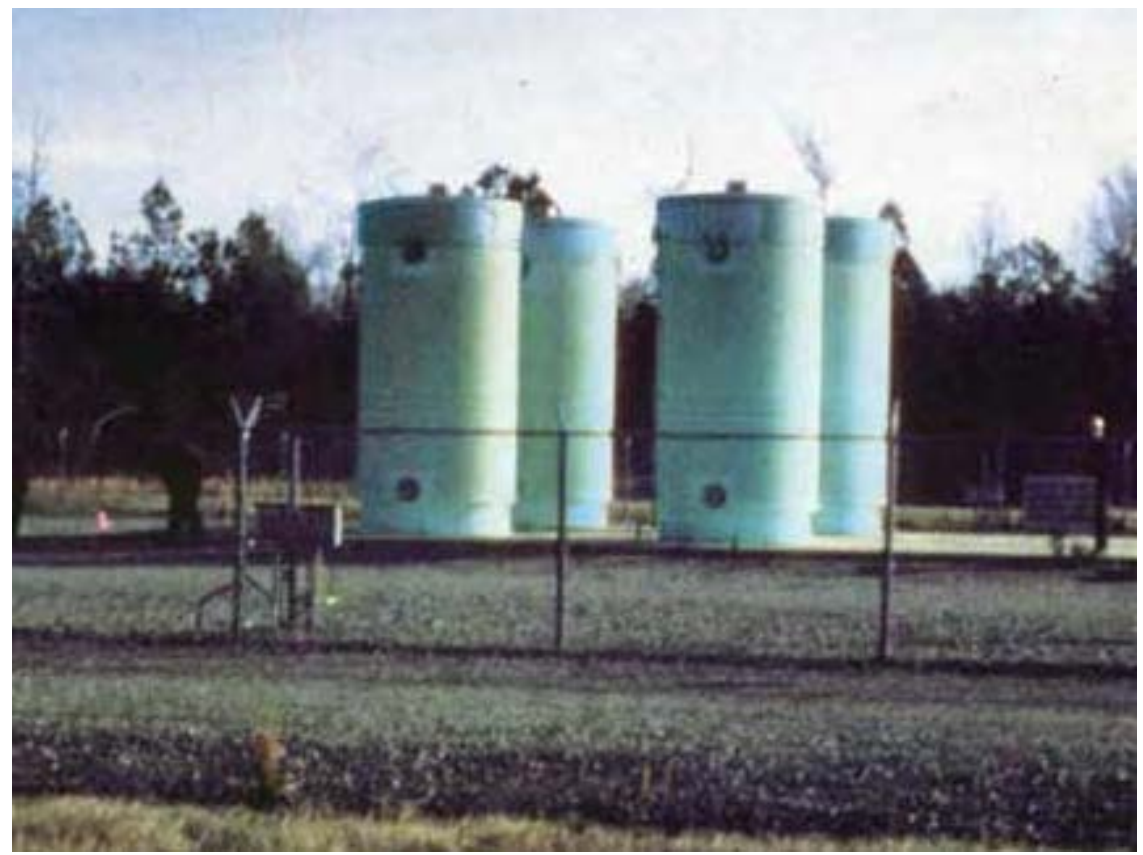

Figure 2. CASTOR V (Interim storage facility Surry).

approximately 10 GWeof total capacity of 100 year operating NPPs with reactors SVBR-100.

\section{Conclusion}

- SNF management is an NP postponed problem that has not been solved in full in any country in the world. It is possible to find the most complete solution to that problem when the closing of the NFC is realized and a large number of FRs are implemented in the NP structure.

- At present, it is difficult to determine the real time when the implementation of FRs operating in the closed NFC is becoming economically expedient. That period is determined by economically available resources of natural uranium and economic characteristics of FRs and closed NFC. For that reason, it is a universal practice of SNF storing in cooling water pools and then in "dry" storage facilities on the NPP sites or centralized repositories.

- For operated LBC cooled reactors, which operated at NSs, the practice of long storage of unloaded cores in long storage tanks filled with solidified LBC was successfully realized. Under such storage, the four defense-in-depth barriers are formed on the way of radioactivity release into the environment, namely: fuel matrix, fuel element cladding, solid LBC and tank casing. And that is assuring the high level of safety.

- It is expedient to consider the similar solution for reactors SVBR-100, in which LBC is replaced by lead providing the higher level of effective protection due to its higher melting temperature. The duration of such storage can reach several decades when the realization of the closed NFC is becoming economically efficient. 
- On the site, which square is $200 \times 200 \mathrm{~m}^{2}$, it is possible to place 13000 tons of the SNF that corresponds to approximately $10 \mathrm{GWe}$ of total power capacity of 100-year operating NPPs with reactors SVBR-100.

\section{Acknowledgements}

The authors would like to thank SSC RF-IPPE employees S.V. Budarina, K.G. Melnikov, for the assistance in preparation of the present Paper.

\section{Conflicts of Interest}

The authors declare no conflicts of interest regarding the publication of this paper.

\section{References}

[1] Novikova, N.N., Komlev, O.G. and Toshinsky, G.L. (2006) Neutronic and Physical Characteristics of Reactor SVBR-75/100 with Different Types of Fuel. Proceedings of ICAPP 06, Reno, NV, USA, 4-8 June 2006, Paper No. 6355.

[2] Zrodnikov, A.V., Toshinsky, G.I., Dragunov, Yu.G., Stepanov, V.S., et al. (2006) Nuclear Power Development in Market Conditions with Use of Multi-Purpose Modular Fast Reactors SVBR-75/100. Nuclear Engineering and Design, 236, 1490-1502. https://doi.org/10.1016/j.nucengdes.2006.04.005

[3] Zrodnikov, A.V., Toshinsky, G.I., Komlev, O.G., et al. (2011) Fuel Cycle for Reactor SVBR-100. Journal of Materials Science and Engineering B, 1, 929-937.

[4] Report on Phase 1A of the International Project on Innovative Nuclear Reactors and Fuel Cycles (INPRO) (2003) Guidance for the Evaluation of Innovative Nuclear Reactors and Fuel Cycles, IAEA-TECDOC-1362.

[5] Klaus Yanberg and Frank fon Hippel (2017) Dry Interim Container Storage of SNF as an Alternative to Its Reprocessing. Journal Atomnaya Strategiya XXI, 127, 6-9. (in Russian)

[6] Yucca Mountain Science and Engineering Report, Rev. 1. (2002) Executive Summary, U.S. Department of Energy, DOE/RW-0539.

[7] MIT Report of the Future of the Nuclear Fuel Cycle (2011) An Interdisciplinary MIT Study.

[8] MIT Report of the Future of Nuclear Power (2003) An Interdisciplinary MIT Study. http://web.mit.edu/nuclearpower/pdf/nuclearpower-full.pdf

[9] Nuclear Electricity. Uranium Information Center (2000) 6th Edition, Chapter 3.

[10] Uranium (2007) Resources, Production and Demand. Red Book Reporting. A Joint Report by the OECD Nuclear Energy Agency and the International Atomic Energy Agency (2008), NEA No. 6345.

[11] Sazonov, V.K., Toshinsky, G.I., Stepanov, V.S., et al. (1998) Technology and Experience of Repair Works and Refuelings for the Nuclear Power Installations with Lead-Bismuth Coolant. Paper in the Book by Georgii Toshinskii, "Lead-Bismuth Cooled Fast Reactors (Collection of Selected Articles and Papers", LAMBERT Academic Publishing (2017-01-18 ISBN-13: .978-3-330-02561-5). 


\section{Abbreviations and Acronyms}

BN: Sodium Fast Reactor

BR: Breeding Ratio

EIPU: Experimental-Industrial Power Unit

FR: Fast Reactor

HLMC: Heavy Liquid-Metal Coolant

IAEA: International Atomic Energy Agency

ITPC: In-Plant Transport-Package Container

LBC: Lead-Bismuth Coolant

LST: Long Storage Tank

LWR: Light Water Reactor

MA: Minor Actinides

MIT: Massachusetts Institute of Technology

MOX fuel: Mixed Oxide Uranium-Plutonium fuel

NC: Natural Circulation

NFC: Nuclear Fuel Cycle

NFM: Nuclear Fissile Materials

NP: Nuclear Power

NPP: Nuclear Power Plant

NS: Nuclear Submarine

PA: Production Association

RAW: Radioactive Waste

RCH: Reinforced Concrete Hood

RF: Reactor Facility

SFSA: Spent Fuel Sub-Assembly

SNF: Spent Nuclear Fuel

SNFS: Spent Nuclear Fuel Storages

SRU: Spent Removable Unit

SVBR: Lead-Bismuth Fast Reactor

TPC: Transport-Package Container

TR: Thermal Reactor

TST: Temporal Storage Tank

VVER (PWR): Pressurized Water Reactor 